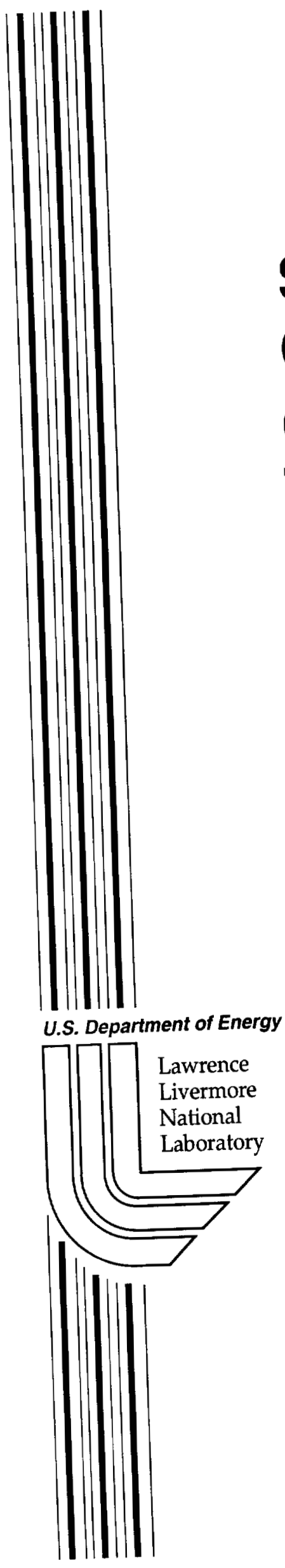

UCRL-ID-147653

\title{
Synchrotron Radiation Computed Tomography (SRCT) of Ruled Laser Targets
}

\author{
J. H. Kinney, D. L. Haupt
}

March 15, 2002 


\section{DISCLAIMER}

This document was prepared as an account of work sponsored by an agency of the United States Government. Neither the United States Government nor the University of California nor any of their employees, makes any warranty, express or implied, or assumes any legal liability or responsibility for the accuracy, completeness, or usefulness of any information, apparatus, product, or process disclosed, or represents that its use would not infringe privately owned rights. Reference herein to any specific commercial product, process, or service by trade name, trademark, manufacturer, or otherwise, does not necessarily constitute or imply its endorsement, recommendation, or favoring by the United States Government or the University of California. The views and opinions of authors expressed herein do not necessarily state or reflect those of the United States Government or the University of California, and shall not be used for advertising or product endorsement purposes.

This work was performed under the auspices of the U. S. Department of Energy by the University of California, Lawrence Livermore National Laboratory under Contract No. W-7405-Eng-48.

This report has been reproduced directly from the best available copy.

Available electronically at http://www.doc.gov/bridge

Available for a processing fee to U.S. Department of Energy

And its contractors in paper from

U.S. Department of Energy

Office of Scientific and Technical Information

P.O. Box 62

Oak Ridge, TN 37831-0062

Telephone: (865) 576-8401

Facsimile: (865) 576-5728

E-mail: reports@adonis.osti.gov

Available for the sale to the public from

U.S. Department of Commerce

National Technical Information Service

5285 Port Royal Road

Springfield, VA 22161

Telephone: (800) 553-6847

Facsimile: (703) 605-6900

E-mail: orders@ntis.fedworld.gov

Online ordering: http://www.ntis.gov/ordering.htm

\section{OR}

Lawrence Livermore National Laboratory

Technical Information Department's Digital Library

http://www.llnl.gov/tid/Library.html 


\title{
Synchrotron Radiation Computed Tomography (SRCT) of Ruled Laser Targets
}

\author{
J.H. Kinney and David L. Haupt
}

Report on the suitability of synchrotron radiation for NIF characterization

Corresponding author:

J.H. Kinney, L-333

(925)-422-6669

kinney3@llnl.gov 


\section{Introduction:}

High spatial resolution tomography benefits from a high brightness source (photons/( $\mathrm{mr}^{2}$ x source area)). ${ }^{1,2}$ A synchrotron radiation source provides extremely high continuous brightness with spectral characteristics suited to a wide variety of imaging needs. Therefore, during the initial testing of the new synchrotron radiation computed tomography (SRCT) system at Stanford Synchrotron Radiation Laboratory, it was suggested that we image a ruled target designed for NIF experiments. This is a detailed report of that imaging effort.

\section{Materials and Methods:}

A ruled, 1-mm diameter laser target of known construction was selected for imaging. The target was made of polyimid, with a brominated central insert. The surface had a three-dimensional sinusoidal pattern similar to that seen in an egg carton. The ruling was designed to have a $50 \mu \mathrm{m}$ period, and have a peak to valley height of $5 \mu \mathrm{m}$.

The specimen was placed on the rotating stage of the SRCT system at beamline 10-2 at Stanford Synchrotron Radiation Laboratory, ${ }^{3}$ and scanned in 0.25-degree rotational increments over $180^{\circ}$. A double crystal Si (220) monochromator was used to select an $\mathrm{X}$-ray energy of $12 \mathrm{keV}\left(\triangle \mathrm{E} / \mathrm{E}<10^{-4}\right)$.

$\mathrm{X}$-rays were converted to visible light on a polished, single crystal cadmium tungstate scintillator. A thermoelectrically cooled CCD detector (Roper Scientific) acquired the visible light images. Image acquisition time was about 0.5 seconds per angular increment. Total imaging time was one hour (see discussion). A parallel reconstruction method using Fourier-filtered back projection generated a threedimensional image of the specimen.

After reconstruction, a threshold was used to define the surface of the laser target. A cord was then generated from a reference plane above the sample to the surface at each $(\mathrm{x}, \mathrm{y})$ voxel in the slice plane. A least squares fit to a plane was performed on the $(x, y)$ array of cord lengths, and the value of the plane was then subtracted from the cord length to correct for any misalignment of the specimen surface with respect to the reference plane. The corrected cord lengths formed a topographic map of the target surface.

\section{Reference Plane}

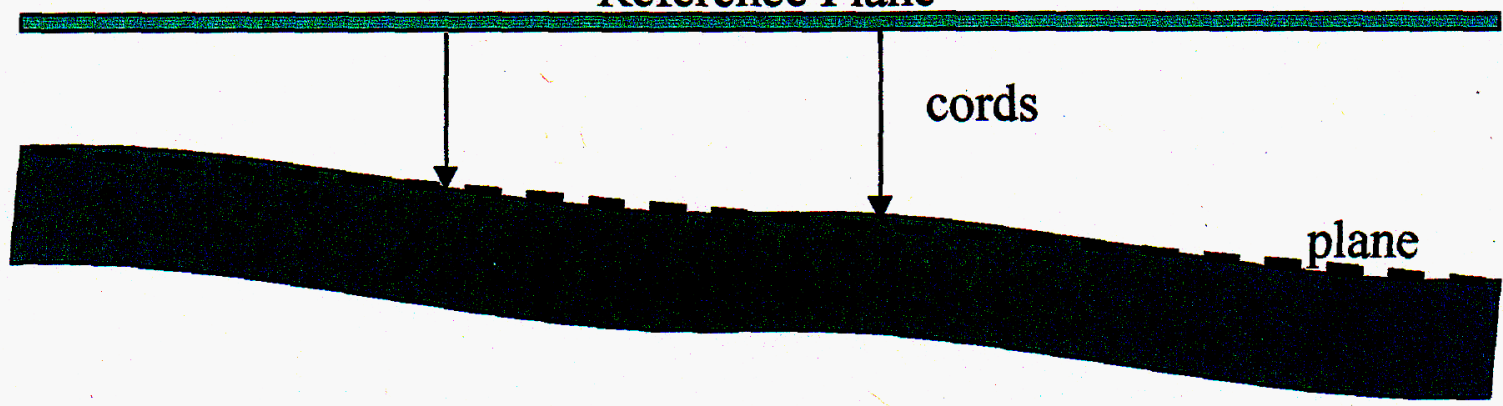

Figure 1: diagram showing the method used to map the surface topography.

Results: 
As a result of the large contrast between the $\mathrm{Br}$ doped insert and the unbrominated pad, it has proved difficult to display a topographic image of the entire part in a single image. Therefore, we have chosen to display the insert separately. The sinusoidal pattern of the insert is clearly seen in Figure 2 . The surface topography along the datum line is shown in the graph to the right. The period spacing averaged $56.3 \mu \mathrm{m}(+/-5.1)$ and the peak-to-valley height averaged $5.7 \mu \mathrm{m}(+/-0.9)$ (averaged from line intercepts perpendicular to the rule). These measurements are in line with the target specifications. ${ }^{4}$

An underlying sinusoidal pattern runs orthogonal to the strong rule pattern seen in Figure 2. This underlying pattern, measured along a trough shown by the datum line in Figure 3, has a sinusoidal nature with a mean peak-to-valley height of $5.4 \mu \mathrm{m}(+/-1.3)$ (averaged from line intercepts perpendicular to the rule) and a period spacing of $97 \mu \mathrm{m}$ $(+/-1.4)$. These features were later confirmed visually.

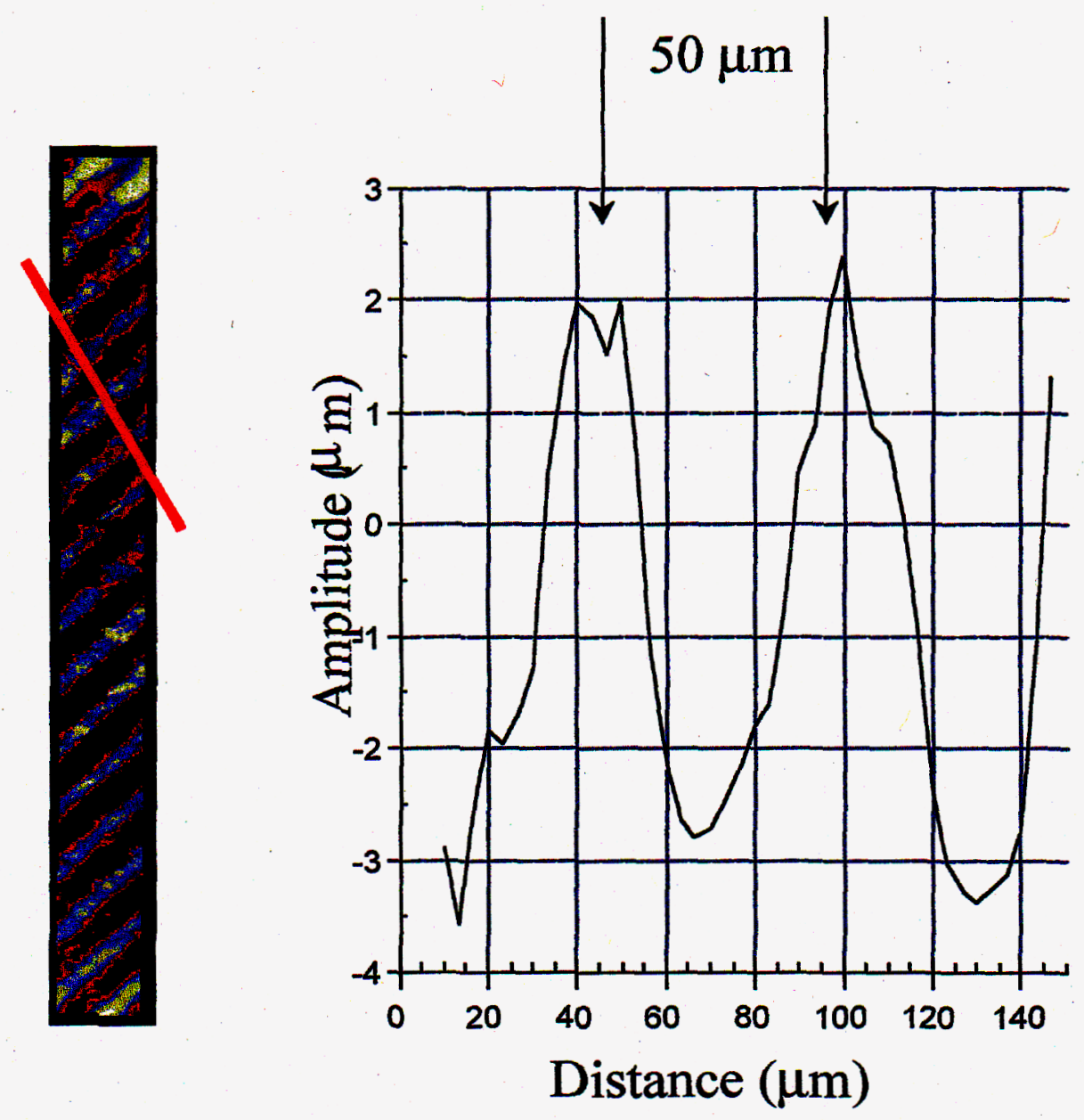

Figure 2: Left, a CT image of the insert surface. Right, a graphical presentation of the surface height along the datum line perpendicular to the upper rule pattern. The amplitude is with respect to the mean surface elevation. 

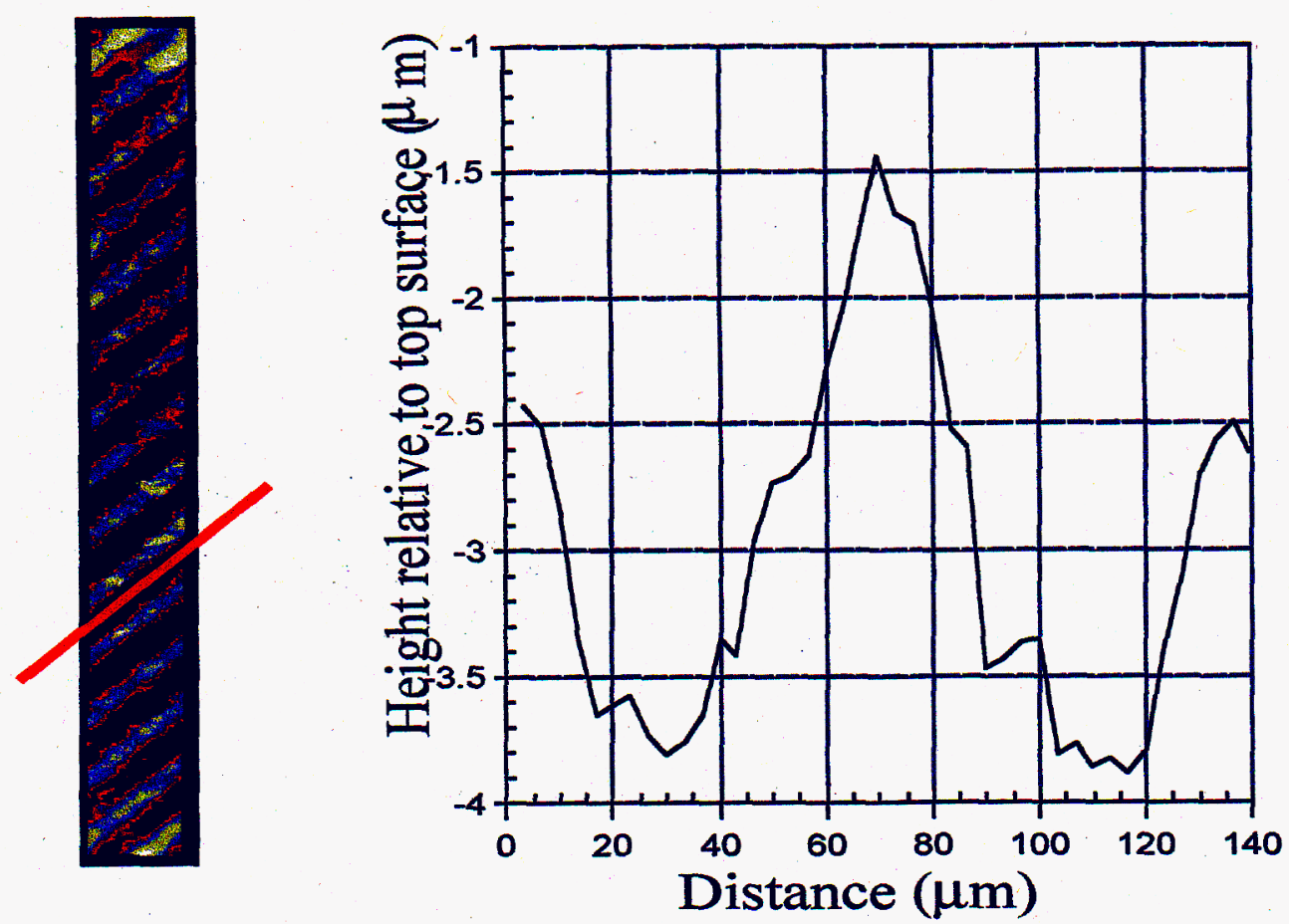

Figure 3: Left, the CT image of the insert. Right, a graphical representation of the surface height along the datum line parallel with the upper rule showing a wavelength twice that of the upper grating. Only a single peak is fully shown. The negative heights indicate that the surfaces lie below the mean surface elevation.

The unbrominated pad was more difficult to image, largely because of the extreme $\mathrm{x}$-ray contrast of the insert. In future, an $\mathrm{X}$-ray energy just below the $\mathrm{Br}$ edge would provide better contrast. A small section of the pad is shown in Figure 4, with a corresponding graph of the surface height along the datum line perpendicular to the rule. In contrast to the insert, the mean peak-to-valley height was $3.8 \mu \mathrm{m}(+/-0.4)$. The period spacing also appeared to be different: $68.4 \mu \mathrm{m}(+/-5.5)$. Topographic measurements in the trough were more difficult to make. Here, the period spacing was $81 \mathrm{~mm}(+/-6)$ with a mean peak-to-valley height of $3.1 \mu \mathrm{m}(+/-0.8)$. 

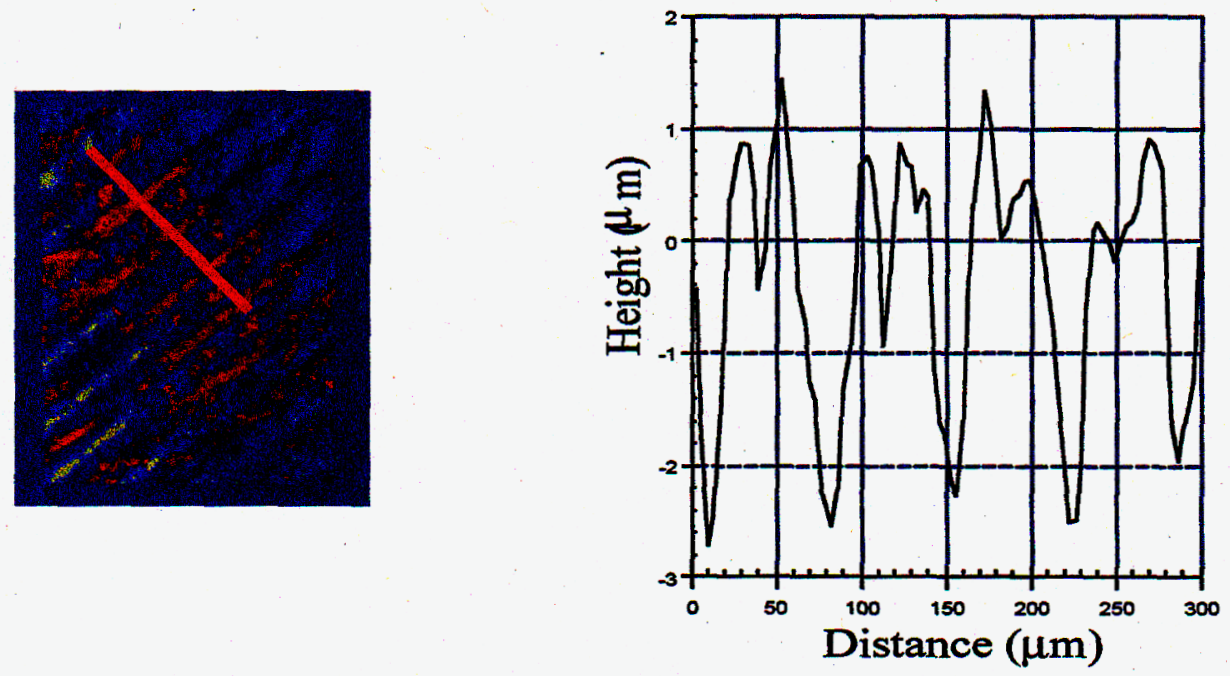

Figure 4: Left, a CT image of the unbrominated pad. Right, a graphical representation of the surface height along the datum line perpendicular to the upper rule.

\section{Discussion:}

SRCT was performed on the ruled laser target prior to our obtaining information of its composition. Compositional information would have allowed us to select a more optimum energy for imaging both the unbrominated pad and the brominated insert. Also, as this was a shakedown run, we did not have software control of the camera binning. All of the images were obtained with a binsize of two. Therefore, the resolving power of the camera was only half its designed maximum.

With traditional x-ray sources, exposure time is the limiting factor in data acquisition. With SRCT, however, exposure times are quite short (less than a second). Therefore, the time spent in reading the camera and moving the stages becomes the limiting factors in acquisition. In this study, $75 \%$ of the acquisition time was spent in activities other than exposing the image. The present version of the software was never optimized to take full advantage of the CCD camera; onboard memory was not used in image storage and partial frame readout was not utilized. Since this study, a new version of the data acquisition software has been produced that markedly speeds up hardware aspects of the data acquisition. We anticipate that camera readout and stage motion will no longer be a limiting factor in SRCT. 
In spite of these limitations, SRCT shows itself to be capable of imaging surface relief to within a couple of microns without adopting any advanced imaging methods. With the new liquid nitrogen cooled monochromator that was recently put into service on beamline 10-2, the exposure time will be ten times shorter $(50 \mathrm{~ms})$. Under optimized conditions, we anticipate that as many as 2-3 specimens could be 3-dimensionally imaged per hour.

Future designs call for the development of a dedicated imaging beamline at the Advanced Light Source at Lawrence Berkeley National Laboratory. The design allows for the insertion of an X-ray microscope if a user base can be established. In the microscope design, $\mathrm{KB}$ reflecting optics will be used as condensers, and a focusing Fresnel zone plate will be used as an objective lens. The spatial resolution of this system is conservatively estimated to be $0.1 \mu \mathrm{m}$ with a field of view of $1 \mathrm{~mm}$.

\section{References:}

1. Kinney, J. H. \& Nichols, M. C. X-Ray Tomographic Microscopy (XTM) Using Synchrotron Radiation. Annual Review of Materials Science 22, 121-152 (1992).

2. Kinney, J. H. et al. The X-Ray Tomographic Microscope - 3-Dimensional Perspectives of Evolving Microstructures. Nuclear Instruments \& Methods in Physics Research Section a-Accelerators Spectrometers Detectors and Associated Equipment 347, 480-486 (1994).

3. Karpenko, V. et al. Beamline-10 - a Multipole Wiggler Beamline at SSRL. Review of Scientific Instruments 60, 1451-1456 (1989).

4. Pete Davis (LLNL) private communication. 